\title{
The Cultivation Mode about the Ability of Scientific Research of Undergraduate Based on the Dual-Tutorial System
}

\author{
X.D. Yuan \\ Materials Science and Engineering Institute \\ Shandong Jianzhu University \\ Jinan ,Shandong
}

\author{
J. Li \\ Yantai Lubao Steelpipe Co., Ltd \\ Yantai, Shandon
}

\author{
G.L. Yuan \\ Jinan Engineering Quality and Work Safety Supervision Station \\ Jinan, Shandong
}

\begin{abstract}
The dual-tutor system is a talent training mode under the Education Reform. Recent years, Institute of Materials Science and Engineering in Shandong Jianzhu University, has began to implement the dual-tutor system to improve comprehensively the quality of students. The cultivation mode about the capacity for undergraduate scientific research based on the dual-tutor system was discussed in detail through students' second class, open trials and the interest group of research. It is proved that students' capacity for scientific research has improved significantly.
\end{abstract}

Keywords-the dual-tutor system; open trials; undergraduate; capacity for scientific research

\section{INTRODUCTION}

The undergraduate tutor system originated from Oxford of England. Its originator was William·Wickham, the bishop of Winchester, who founded the "New School" at the beginning of the 14th century. It refers to a teaching system under the two-way selection between teachers and students. The teacher, who has a high level of expertise and possesses both political integrity and ability, can conduct an individual guidance aiming at students' learning, morality, life and psychology. The tutor system of Oxford brought a new revelation to talent training of Chinese universities. Peking University was regarded as an experimental unit to begin trying the tutor system in 2002. At present, with the education reform of high school progressing, there have been a variety of tutor system: masters tutor system, doctors tutor system, the head teachers system, the whole people tutor system, the whole journey tutor system, the scientific research tutor system, etc. [1]. Under a variety of tutorial system, the work of counselors and professional teachers is not clear, division of labor unclear and work often repeated, which directly affect the development of students' school work and interest of research. This paper mainly takes the Institute of Materials Science and Engineering of Shandong Jianzhu University as example, to discuss the cultivation mode on the capacity for undergraduate scientific research based on the dual-tutor system.

\section{THE CONNOTATION AND THE IMPLEMENTATION PROCESS OF DUAL-TUTOR SYSTEM}

Since 2006, the Institute of Materials Science and Engineering of Shandong Jianzhu University has began to try to implement dual-tutor system, whose main core thought was that the freshman and sophomore took ideological and political mentor - counselor as the principle thing; juniors and seniors regarded professional instructors - youth teachers as the prime thing. Explorations in this area have also been reported about other brother universities [2]. Students should be allowed to actively participate in teachers' research projects. Counselors' ideological guidance and professional teachers' guidance could be combined together organically through scientific research projects. This is conducive to managing students' daily life and improving the level of scientific research. The specific pattern is shown as Figure1. The significance of encouraging students of colleges and universities to actively participate in teachers' research projects is obvious [3-8].

Counselor is the main tutor of undergraduates during the freshman and sophomore year, who mainly takes charger of students' life, learning, work-study, the Party construction, campus culture and so on. During the freshman year, counselor divides students into different interest groups of scientific research based on the classification and their interest in the direction of their major, inviting different experts and professors with higher level of scientific research to give lectures according to different interest groups of scientific research. During the sophomore year, counselor should carry out a series of Design Competitions about students' career planning and Design Competitions about students' study arrangements according to different interest groups of scientific research, to help students identify good scientific research interest and build self-confidence.

At the first semester of the junior, the principle of "two-way selection" is adopted to carry out mutually selecting between students and tutors. Students select their tutors based 
on major interests of their own and the research direction of teachers; teachers select students according to requirement of their issues and students' performance. The tutors of the students during the juniors and seniors year, are mainly the youth teachers, who mainly take charge of guiding students' major, cultivating their professional interests, improving the level of scientific research, etc. During the junior year, the tutors should actively encourage and guide students to participate in the nationwide undergraduates "Challenge Cup" Competition, the Casting Technology Design Contest, Concrete Design Competition etc, to encourage students to write academic papers. During the summer vacation, tutors should lead students to take part in " Substituted Post Internships" of social practice in summer and academic "Open Experiment" activities, to make them penetrate deep into enterprise and laboratory, to help them understand the expertise needs of the future work, to know the precautions and the process of operating the experimental apparatus, etc, to further enhance students' interest in their major and to improve students' capabilities in scientific research.

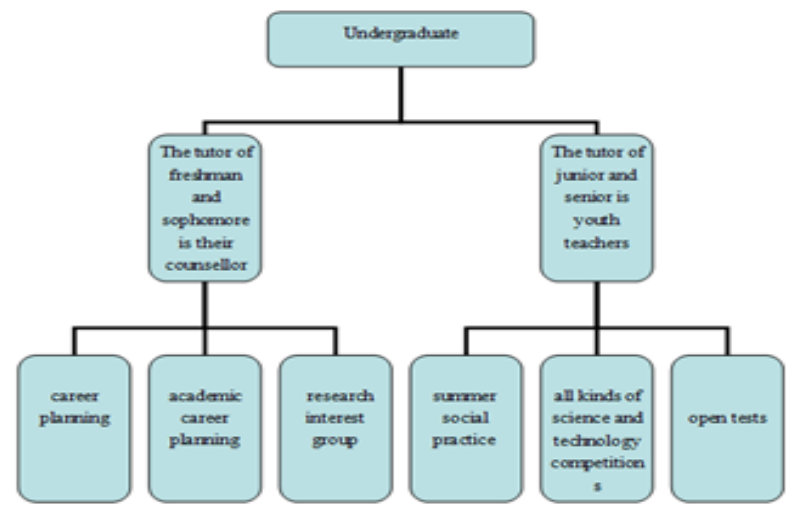

FIGURE I. THE CULTIVATION MODE OF UNDERGRADUATES' RESEARCH CAPACITY UNDER DUAL-TUTOR SYSTEM.

\section{The Cultivation Mechanism of Students' ABILITY ON SCIENTIFIC RESEARCH BASED ON THE DUAL-TUTOR SYSTEM}

\section{A. Guide Students to Do Well on Study Planning}

On the condition of knowledge economy, the inexhaustible motive force for national economic development is that the innovation ability on scientific research of the successor under Socialist Modernization improves continually. For undergraduates to be as successor, it's imperative to improve themselves innovation capability on scientific research. In order to improve undergraduates' innovation ability on scientific research under the dual-tutor system, firstly tutors should do well on the students' academic guidance and guiding light. The Institute of Materials Science and Engineering of Shandong Jianzhu University, takes the dual-tutor system as guarantee, constantly pursuing improving students' research capabilities. Tutors establish different research interest groups according to different professional direction, such as: surface engineering group, casting group, mold design group, future welding group, metal materials group, green building team, CAD design teams, etc. And 30 research interest groups are included and each group has about 20 students. Then tutors invite specialists and scholars on different research directions at home and abroad, to make professional reports depending on different research interest groups in order to enhance students' professional self-confidence. Every year about 40 specialists and scholars at home and abroad are invited to give different professional research reports. Students respond enthusiastically and the degree of participation is high. Finally, tutors establish evaluation form on students' profession comprehensive quality, according to students' performance in learning and life, the student leaders' feedback, as well as in-depth investigation on various professions. And reframe Design Competitions about students' career planning and Design Competitions about students' study arrangements to adjust students' profession direction, to enhance students' professional self-confidence, and to lay a solid foundation for improving students' research capacity .

\section{B. Encourage Students to Participate in the Second Class}

The second class is the best place where students put their professional knowledge into practice. Under the circumstances that Shandong Province is a big Province on manufacturing, the Institute of Materials Science and Engineering establishes the second class based on "research, practice, internship, teaching, and employment" relying on 20 enterprises, such as The Casting Association, The Surface Engineering Association, The Machinery Industry Association, The Academy of Sciences, The Limited Company of the King Kintai Casting in Shandong Province. The ideograph of the second class in the Institute Materials Science and Engineering is shown in Figure 2.

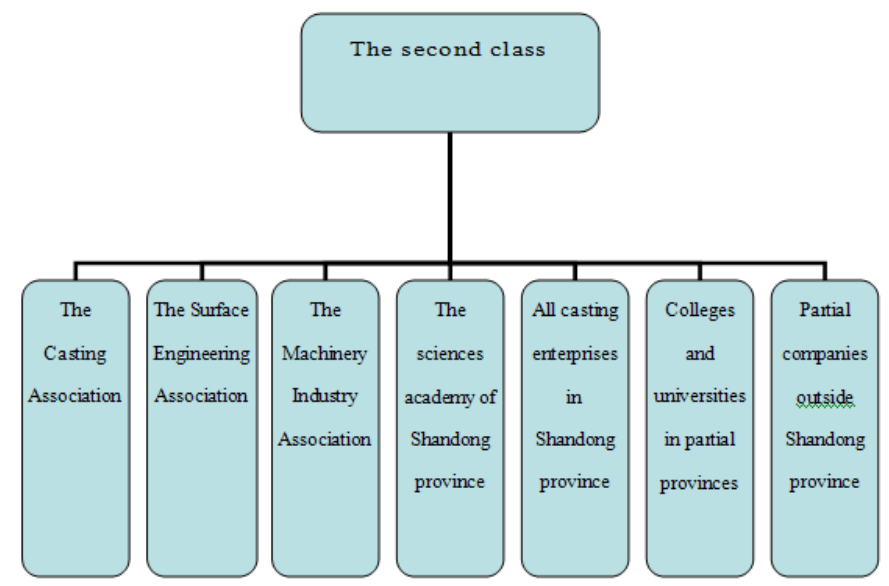

FIGURE II. THE SERVING MODE ON UNDERGRADUATES' SECOND CLASS.

The youth teachers are utilized as professional tutors to organize students to construct the second class, based on the form of "substituted post internship" organizing students to penetrate into enterprises, to understand their requirements, to know the relation between company and profession in order to further enhance students' professional ability; taking a series of undergraduate competitions such as "Challenge Cup" and the casting design competition like "The Perpetual Championship Cup" as the leader to encourage students to take part in research projects to improve the capacity for scientific research; regarding “Open Experiment” as possy, to 
organize students to know well the experimental procedure, the instruments' operation, combining the experimental knowledge with theoretical knowledge organically.

\section{THE RESEARCH CAPACITY OF STUDENTS IS} SIGNIFICANTLY IMPROVED UNDER THE DUAL-TUTOR SYSTEM

\section{A. Students' Employability is Significantly Enhanced}

Based on the dual-tutor system and two-way managements and services for students, students' employability is also enhanced with their research capacity significantly improved. Recent three years, the graduates' first signing rate is more than $95 \%$ and the overall signing rate is $100 \%$ of the two majors in the Institute of Materials Science and Engineering. The employment companies are mainly National Nuclear Power, North Heavy Industries, China Railway Engineering Corporation, China Construction Group, Baosteel, Jinan Steel, Shandong Electric Power Group and other large enterprises. The mainly postgraduate universities are Tsinghua University, Harbin Institute of Technology, Beijing University of Aeronautics and Astronautics, Chinese Academy of Sciences, Shandong University and other renowned institutions. Especially in 2010, the number of the graduates who are admitted to the universities graduated as 211 and 985 universities, were 59 in all, accounting for about 20\%. The number of the students who get a job from domestic famous enterprises is 52, accounting for about $17.6 \%$.

\section{B. Students' Research Achievement is Brilliant}

Student's research capacity in dual-tutor system has been significantly improved, and their capacities on operating instruments, designing experiments, and writing papers have been improved significantly. Recent three years, the enthusiasm of students participating in social practice and various competitions is very high. There is a phenomenon that one teacher leads more than one team. Recent three years, students have achieved remarkable achievements in the social practice, technology innovation and other activities. 4 people have obtained the name of advanced individual in social practice of Shandong Province. 128 people have won the title of advanced individual in social practice of Shandong Jianzhu University. The number of awards with National Level in Science and Technology Competition like "Challenge Cup" is 7, in addition, 38 awards with provincial level, 4 patents for invention authorized by nation, 18 new type patents, and 14 academic papers first published (EI indexed).

\section{CONCLUSIONS}

Through different guidance of counselors and youth teachers, the talent cultivation mode under the dual-tutor system explores the cultivation mechanism on undergraduates' capacity for scientific research, to establish a more comprehensive research cultivation mode and effectively to improve the students' research capabilities, from students' research interest groups, career planning, academic career planning, social practice, science and technology competition, open-label trial, etc.

\section{ACKNOWLEDGEMENT}

Fund for the College science and technology plan of Shandong Province (Project No. J12LA11).

\section{REFERENCES}

[1] Wenqiang Zheng, Qian Ding, The first exploration on how the tutor system of research type impacting undergraduates' research level, The academic journal on Henan Staff medical college. 23 (2011) 762-763.

[2] Weizhong Liang, Zhenting Wang, etc. exploration for the training mode under undergraduate dual-tutor system about the major of Material Molding, Casting equipment and technology. 4 (2011) 33-34.

[3] Li Zhen,Yun Xue. Research on approaches of cultivating students' abilities based on undergraduate research projects, Talents training. 216 (2011) 27-29.

[4] Qinmin Xu, Tao Zhang. Quality training and practice of innovative and entrepreneurial undergraduates learning Engineering Majors, Laboratory Science. 14 (2011) 4-6.

[5] Baoliang $\mathrm{Bi}$, Ying Chen,etc. approaches and suggestions on undergraduates participating in research, The academic journal of Yunnan Agricultural University. 5 (2011) 87-91.

[6] Shengyi Jiang, Empirical Study on training undergraduates' research ability, The academic journal of Guangdong University of Foreign Studies. 22 (2011) 96-99.

[7] Wanrong Gu, Ji Sun, etc. reflection on improving cultivation mechanism of undergraduates' research innovationton ability, Education and Teaching Management. (2011) 24-27.

[8] Haiping Lu. Analyze the factors affecting undergraduates' research and innovation abilities, The academic journal of Chongqing University of Science and Technology. 20 (2011) 163-164. 